\title{
Editorial preface to the paperback edition
}

\section{The Handbook of Standards and Resources for Spoken Language Systems}

has been published as a single volume hardbound library edition and as two hypertext editions. The first hypertext version is supplied on a CD-ROM together with the Handbook. It includes browser software for a number of different working environments, and was created mainly with the aim of providing efficient local online consultation. The second hypertext version is available on the World Wide Web at the publisher's Web site, and is designed for initial and occasional consultation via the Internet.

Discussion of the pros and cons of electronic versions, in particular of the Web version, in consultation with the EAGLES project organisers, the European Commission, the publisher, and potential users, led to the idea of producing four paperback volumes corresponding to the four parts of the Handbook. It was felt that smaller and cheaper paperback versions would have several advantages, including the following:

1. Publishing the parts as single paperback volumes would be less expensive than the single hardback volume for those with selective needs, and would make it possible to use the parts as textbooks for courses in spoken language technology, phonetics and linguistics.

2. Paper versions are durable, more portable, and (perhaps most important) easier to annotate than electronic versions.

3. Books are ergonomically superior to electronic versions for continuous study.

4. Inexpensive paperbacks are more accessible to users outside the wealthier nations.

Care has been taken in the production of the paperback version to ensure that each volume can be used autonomously, but also to ensure that at the same time it retains its character as a part of the overall Handbook. For these reasons, each volume of the paperback edition contains the general preface and the 'User's Guide' of the Handbook, as well as the Glossary and list of Abbreviations. The text and page divisions of the paperback edition correspond to those of the single volume Handbook, though pagination differs (see below).

Each volume of the paperback edition contains the material from one of the four Parts of the Handbook. The table of contents, bibliography and index, as well as chapter numbering and pagination are also specific to the individual volumes.

The following features have been introduced for the guidance of the reader:

1. The volume number is printed on the even page running header lines.

2. On each page the number of the corresponding page in the Handbook is placed in square brackets next to the volume page number.

3. Cross-references between chapters have been retained, and references to 
vi Editorial preface to the paperback edition

chapters in the same volume are cross-referenced in the normal way by chapter number. Chapters in the other paperback volumes are referenced by prefixing the volume-specific chapter number with the volume number as an upper case roman numeral: for example, 'III:5' refers to the chapter on 'Assessment of synthesis systems', Chapter 12 in the Handbook.

The chapter numbering of Volume I and the appendix lettering in Volume IV of the paperback edition are identical to those in the Handbook. The chapter numbers in Volumes II and III of the paperback edition correspond to the chapter numbers in the Handbook as follows:

Chapter

User's Guide

Spoken language lexica

Language models

Physical characterisation and description

User's Guide

Assesssment methodologies and experimental design

Assessment of recognition systems

Assessment of speaker verification

systems

Assessment of synthesis systems

Assessment of interactive systems

\section{Paperback Handbook}

II:1 Chapter 1

II:2 Chapter 6

II:3 Chapter 7

II:4 Chapter 8

III:1 Chapter 1

III:2 Chapter 9

III:3 Chapter 10

III:4 Chapter 11

III:5 Chapter 12

III:6 Chapter 13 